\title{
We Were Residents Once ... And Young
}

\author{
Nicholas Teman, MD and Curt Tribble, MD \\ Division of Cardiac Surgery, University of Virginia, Charlottesville, VA, USA
}

\section{INTRODUCTION}

To achieve great things two things are needed: a plan and not quite enough time.

-Leonard Bernstein

Each transition in the trajectory of a career comes with changes, some good, some challenging, and some changes are both. As you prepare to enter a Thoracic and Cardiovascular Surgery Residency (TCV Surgery), or the last few years of an Integrated Six Residency, you are well aware that you are likely embarking on one of the most demanding and challenging eras of your professional life. And, you are likely also aware that, as a TCV Surgery resident, you will have a limited amount of time to approximately double what you know about medicine and surgery. In fact, in these last few years of your formal training you will likely have fewer than 700 days to accumulate this necessary medical and surgical knowledge.

I was born for this moment and for all the days abead. I will be tested far beyond anything I have imagined..... I am to undergo an ordeal .... But I have, I hope, no illusions. I expect an ordeal, an ordeal of grandeur.

—Webb Chiles, Storm Passage

You would not have matched into a TCV training program if your once and future mentors did not believe that you were capable of meeting these challenges. Having not only had your job ourselves but having also seen many of your predecessors navigate these waters, we have some ideas and strategies that we believe will help you become capable, versatile, and knowledgeable TCV surgeons. In addition, we will suggest some ways that you can maintain your health, humanity, and sanity while you make your way through this phase of your training, which we believe you will come to view as an ordeal of grandeur.

However, before getting into passing along detailed advice, we would also like to emphasize that we all must pay attention, at every turn, to the people who will be our patients, as well as to those who care about them. While this admonition may seem self-evident, we are well aware that all of us can sometimes get more caught up in the procedures, getting the

Correspondence: Curt Tribble, MD, Professor of Cardiothoracic Surgery, University of Virginia Health System, Division of Cardiac Surgery, Box 800679, Charlottesville, VA 22908; 434-243-9250 (e-mail: ctribble@virginia.edu). work done, and just plain surviving than is optimal for us or for our patients.

The secret of the care of the patient is in caring for the patient. -Francis W. Peabody

While Dr. Peabody's famous line may seem to pertain more to our colleagues in various primary care settings, we believe that it is important in all arenas in which patients are cared for, including ours. Furthermore, this admonition is not just for the good of the patient. It is also good for all who take care of patients in any realm of medicine.

We recently had the privilege of hearing a presentation by a Thoracic Surgeon who had retired after a long and successful academic career. His talk was entitled 'The Resiliency Bank Account.' [Maddaus] In the relatively short time he had available for this presentation, he understandably focused on the mental and physical aspects of surviving while training in and practicing cardiothoracic surgery. However, we believe it important to not only protect one's energy and sanity in our work but to gain energy and sanity from the work and especially from our interactions with our teams, our patients, and our patients' families. Thus, we like to think more about 'buoyancy' than 'resilience,' a semantic distinction we have learned from the writings of Joan Halifax. [Halifax]

\section{Start where you are, use what you've got, do what you can. -Arthur Ashe}

We were residents once ourselves, of course, one of us about 35 years ago and one about 5 years ago, with our combined medical and surgical educational trajectories having included seven different university programs. Not all that much has changed about how to be a successful and resilient Thoracic Surgery resident between those earlier days and the present day, it seems to us. Therefore, we will attempt to make some suggestions that we hope will be of value to you, as well as to your current and future patients, not only in caring for their immediate needs, both also for the overall well-being of all concerned, including you. Let's get started......

\section{PART I - PREPARING TO START YOUR THORACIC RESIDENCY TRAINING}

Given that The Match for most trainees entering a cardiothoracic residency occurs more than a year prior to matriculating into those programs, what should you be doing to prepare for your Thoracic Surgery Residency in that interval? 
First and foremost, you should, of course, continue to do the job you are doing well, providing good care to your patients and learning as much as possible about what you are engaged in during that time, which is, for most, learning and doing General Surgery. After all, you will most likely be taking your American Board of Surgery written exams just prior to starting into your Thoracic training program. Furthermore, every patient you encounter and each operative case you perform during this final stage of your training in Surgery will not only require your full attention but will also allow you to observe and discuss with your faculty surgeons why they conduct their operations in a certain way or use certain techniques. They will always have an answer to those questions.

However, there are strategies and opportunities to, simultaneously, begin to prepare for your transition to your Thoracic Residency. One specific suggestion is to begin to build your library. We will start with some suggestions for 'lite' reading that may be both useful in your Chief year and helpful in preparing for your future Thoracic Surgery training. Here's a list of some books that may fit that bill:

- Top Knife by Asher Hirshberg \& Kenneth Mattox

- Many Sleepless Nights: The World of Organ Transplantation by Lee Gutkind

- Every Second Counts: The Race to Transplant the First Human Heart by Donald McRae

- Near Misses in Cardiac Surgery by Myles Edwin Lee

- A Little Book of Doctors' Rules by Clifton Meador

- Transplant a novel by John Elefteriades

- The Little Book of Big Performance by Doug Newburg

Here are some other books that should probably be on your bookshelf and perused, at least to some degree, prior to embarking on your Thoracic Residency (each of which is short and relatively affordable):

- The Ventilator Book by William Owens

- Rapid Interpretation of EKG's by Dale Dubin

- The House Officer's Guide to ICU Care by John Elefteriades

- Echo Made Easy by Sam Kaddoura

- Key Questions in Cardiac Surgery by Moorjani, Viola, \& Ohri

- Key Questions in Thoracic Surgery by Moorjani, Viola, \& Walker

In addition to these publications, The Thoracic Surgery Residents Association (TSRA) has developed an excellent set of educational resources for residents, including a variety of useful publications and an assortment of short podcasts. (https://www.tsranet.org/)

You should also try to attend, at least occasionally, pertinent conferences in your institution such as cardiology cath conferences or thoracic tumor boards. These days many of these conferences are virtual, which can make participating in them all the more practical.

One can also sign up to receive the Table of Contents of journals via email, and, in our field, the most useful ones are The Annals of Thoracic Surgery, Operative Techniques in Thoracic and Cardiovascular Surgery, and The Journal of
Thoracic and Cardiovascular Surgery. Glancing at even just a few articles a month, especially review articles and techniques articles, can be surprisingly educational and useful. Many seasoned medical educators similarly also urge learners, at every level and in every discipline, to look at a general medical journal or two regularly, such as The New England Journal of Medicine or The Journal of the American Medical Association. There are almost always articles of interest to cardiothoracic surgeons in these journals.

You likely already have a system for filing articles but, if not, you should create one. We suggest that you separate 'techniques articles' from other clinical articles in your filing system.

While it may seem self-evident, as you move into the early days of the actual Thoracic Surgery residency, you should take full advantage of your more senior residents, as they can help you with almost everything, from how to post cases, how to get an early reading on a radiology study, how to start doing things in the cardiac operating room, and the preferences of the various faculty surgeons with whom you will be working.

\section{PART II - THE PREOP CLINICAL WORK}

The preop consultation should be performed with at least as much care as the actual operation. If you worry about the things that might happen, a lot of the things you worry about won't happen. Book

-Daniel Waters, A Heart Surgeon's Little Instruction

So, you've been asked to consult on a patient that may need an operation or you hear that your attending has posted a case for an in-house patient. You will be the resident on the case. What do you need to do?

First of all, try to determine if the case is actually posted or if you and your team are being asked for an opinion on the patient's care. You will want to form a 'united front' with your attending prior to telling the patient or the patient's clinical team what your recommendations will be. The reason that you need to assure this congruence is that you and your team do not want to give the impression to the patient nor to the primary clinical team that your team has already concluded that an operation is 'in the offing' before you have decided that an operation is, indeed, the best course of action. With that principle established, what you should do, as best you can, based on the available information, is make up your own mind about what operation might be done and, more importantly, if it should be done. As the old saying goes, there are a lot more operations that can be done than should be done.

A surgeon is a doctor who can operate and who knows when not to.

—Theodore Kocher

Therefore, you need to round up and carefully consider as much information as is available about the patient to help weigh the pro's and con's of the contemplated operation, as well as of the alternative therapies that might also be considered. You need to review the results of any cardiac 
catheterization, echocardiogram, or other studies that have been obtained on the patient you are evaluating. And, you need to look at these studies yourself, not just the reports of the studies. You may need to find someone to review them with you, which will often disclose some subtleties that might not be obvious to you or may not be included in the formal reports. You will also want to review all aspects of the patient's medical history, especially any prior operations. (And, if those operations include cardiac operations, you should do your best to find and read those operative notes, as there will almost always be something that was done that will be pertinent to the contemplated therapeutic options.) You will also need to begin to organize a plan to obtain appropriate additional studies that may be needed to sort out a plan for that patient's care. These studies may include a chest $\mathrm{x}$-ray, a CAT scan of the chest, carotid studies, vein mapping, an Allen's test or vascular studies (if the use of a radial artery graft is contemplated), or other vascular studies.

You must perform a focused physical exam on the patient yourself and not depend just on what some junior houseofficer on another service has written in the chart. It is surprising how often something of importance to you and your team will have been overlooked by a primary team. Listen to the patient's heart and lungs. Check the patient's pulses. Listen for vascular bruits and look for venous varicosities. And, never forget to look for old incisions that may provide clues about prior operations or procedures that you will need to know about to properly plan for an operation. After all, it is you who will have to deal with the repercussions of an overlooked, but critical, bit of information, not the primary or referring physicians.

When you have gathered the appropriate information and discussed the case with your supervising surgeon, you need to write a thorough, organized note. It is sometimes best to create such a note as a Word document so that you can add to it as information comes in or decisions are made, prior to pasting it into the electronic medical record. You will want this note to represent what you and your team think is the best course of action, and your goal should be to make your note the 'go to' note representing your team's recommendations and plans. [Tribble, 2019: Are You Making Yourself Clear?] While this kind of preparation can sometimes make you feel more like an internist than a surgeon, it is worth remembering the old adage that a surgeon should be an internist who can operate. Neither you nor your patient will regret this kind of diligent and thorough preparation and contemplation of the patient's issues. And, always remember the old saying: You cannot unoperate.

It is also important to get to know the patient and family, especially if it seems that an operation will likely be offered. A great conversation to have with a patient who is being scheduled for an operation is ask them what they plan to do when they are well again. They will almost always have an answer for that question, and, of course, you will be giving them the subtle message that you expect them to do well with the proposed procedure, recognizing that it can sometimes be challenging to find the right balance of complete disclosure and optimism. [Tribble, 2016, Gimme Three Steps]
The only things certain about surgery are that it is inconvenient, painful, and dangerous.

-James Elsey, MD

At the end of the preoperative conversations, you should promise no more than that you and the patient's other doctors agree that the operation is indicated and that you and everyone on your team will do your best for them. Above all, in these conversations you must strive to avoid giving 'discordant' information to the patient and family. If, however, you realize that they perceive that something someone has said to them does not 'line up' in some way, you must do your best to straighten things out. You may occasionally need to say something like "I don't know, but I will find out." In these conversations, you should strive to convey a blend of confident optimism and pragmatic realism.

The patient's outcome is correlated directly with the surgeon's attention to a myriad of minor details. This obsession with doing a lot of little things right is the foundation for good surgical results.

-Hiram Polk, MD [Whitson, 2016]

Once the plan has been established and the operation is imminent, you should re-review the information you have collected and organized. This review is all the more important if there has been a time lag between the collection of the information and the time for the operation. In other words, consider the patient to be yours and the preparation for that patient's care to be your responsibility. Finally, virtually every faculty surgeon will want you to discuss the case with them the night before the planned operation. [Tribble C, 2016, Failing to Prepare...]

In summary, there will almost always be nuances, unexpected findings, scheduling issues, or other factors to be considered, and it is on you, the senior resident, to pull all those loose ends together.

While we have focused primarily on the preoperative consultation on a patient who is already in the hospital, you will also see such patients in the clinics run by your faculty surgeons. At least you should see some patients there, challenging though it may be to get to the faculty clinics on a regular basis. Participating in clinic is both fun and educational. And, you must recognize that, sooner or later, you will have to run your own clinics, so it behooves you to learn as much as you can from the clinics accessible to you during your training. [Tribble, The Well-Tempered Clinic, 2020]

\section{PART III - THE DAY OF THE OPERATION}

$$
\begin{aligned}
& \text { It's showtime, folks! } \\
& \text {-Joe Gideon, in All That Jazz }
\end{aligned}
$$

On the day of an operation for which you are the senior resident assigned to a particular case, you should strive to see your patient (and, optimally, the family) prior to the patient's being moved into the operating room, especially since, in the current era, this meeting may be your first with the patient. 
You will often need to see them in the preop 'holding area.' One of the most important tasks for this meeting is to ensure that the consent is signed and is up to date. If the consent has not been signed or is missing, you will, of course, need to get it signed at that point. [Tribble, 2019, First, We Do Harm]

You should introduce yourself as 'Dr. So \& So' and say that your attending surgeon, whose name the patient and family will know, has asked you to help with the operation. By stating this fact, you will be acknowledging to them that the expected attending surgeon is, indeed, in charge and that they both need help but also trust you to provide that help. This approach can save time that might otherwise be required if the patient or the patient's family move into 'the 49 questions' mode. [Tribble, Gimme 3 Steps, 2016 \& Tribble, Grandmother Rules, 2017]

As always, anything you can do to put the minds of the patient and family at ease is valuable. However, it is worth noting that there are phrases that are both true and effective and that there are others that are not. For instance, it is always reasonable to say something like "we hope for good things," while it is inappropriate to say something flippant, such as "everything will be fine," which is obviously both untrue and patronizing to the usually fairly savvy patient and family.

Before you head to the operating room, you will, of course, need to give some thought to personal issues, such as getting a drink of water, rounding up your favorite OR shoes, making one last 'pit stop,' and ensuring that you have the right set of loupes for the planned operation. If your operating rooms are on the warm side, you might also consider rounding up a cooling vest, if one is available to you. [Tribble, Clothes in Car, 2016]

You should plan to be in the OR while the anesthesiologists are getting the patient lined up and intubated, as cardiothoracic patients have a way of becoming unstable at these junctures. You may also be called upon to answer questions about supplies or blood availability and about the precise operative plan, given that many of the folks on your team will be meeting and hearing about the patient for the first time at that point. You will want to ensure that any pertinent imaging studies (cath, CT, CXR, angiograms, etc) are readily accessible on that room's computer. You should also help position the patient optimally for the planned procedure, while remembering the old adage that one should not pad pressure points but should pad around them.

We have covered the proper prepping and draping of the cardiac patient in a separate treatise. [Tribble, Median Sternotomy, 2021] Once the patient has been draped, the time out should be conducted. You, as the senior resident, should lead this time out. [Tribble, Crew Resource Management, 2017] There is usually a script or checklist that should be followed. [Systems approach to surgical safety - Calland, Adams, Tribble, 2002] It is essential to review the operative plan, any special instruments or gear that might be needed, and any other considerations unique to your particular patient. Finally, you should acknowledge each person in the room by name, not only to recognize each of them but also to be sure that everyone knows the role of each participant. Occasionally, there will be a team member that is new, or relatively new to the team. It is always gracious to acknowledge and welcome that person to the team.

There are two kinds of residents: those who write things down and those who forget.

-Hermes Grillo, MD

Once you have removed the drapes and doffed your gown and gloves, you should look at your checklist of postoperative 'chores,' which will include creating a brief op note (for which, you will want to have written down perfusion and clamp times, blood administered, the location, size, and quality of the vessels grafted, size of valves inserted, and other observations about the case). A good way to remember and record this type of information is to have a pre-printed checklist in your pocket notebook, which will serve both as a reminder to write down this information and to complete other postoperative tasks, such as creating the formal op note, getting word to the referring doctors, and speaking to the family. Here is an example of a checklist that can be printed out preoperatively, kept in a notebook, and used to note these bits of information, as you are finishing up in the OR:

$\square$ Times: Cardiopulmonary bypass - Cross clamp -

Valve type and size

Blood products administered

Family meeting held

Referring docs notified

Postop CXR reviewed

Formal op note dictated or created

Case recorded in your case log

A 'lessons learned note' jotted down

There is always some 'down time' after you break scrub while the anesthesia team and the nurses prepare the patient for transport. We recommend that you use this time to enter your brief op note and your templated operative note in the EMR and to log your case on the ACGME website, so that both of these important tasks are completed before the patient leaves the room. It is necessary to remember, even if you are able to create the actual op note while waiting for transport, that a 'brief op note' is also required by accrediting organizations.

The patient will then be moved from the operating room to the intensive care unit (ICU), where you, the primary resident, should conduct the handoff of the patient to the ICU team. Of course, you will want to tell them not only what operation has been done, but also any special instructions that may be pertinent to that patient.

Next, you should talk with the family of the patient, if your attending surgeon has not already spoken to them. We think it is optimal for this conversation to take place at this particular juncture, with both the attending surgeon and the resident participating, though that approach is occasionally not possible for a variety of reasons. Remember that it is essential to sit down when talking to families. [Tribble, Grandmother Rules]

After speaking to the family, you should always return to the patient's bedside to check on how things are going, as the initial 'settling' of the patient in the ICU can be a somewhat 
unstable period. As noted above, you should always have on your postop checklist the need to look at the postop chest radiograph yourself, as soon as is practical.

At some point, as soon as feasible after the operation, you should create the formal operative note, if you have not already done so. In an earlier era, these notes were always dictated, and, of course, dictating the operative note remains an option. With the advent of the electronic medical record (EMR), it became apparent to us that one could create a generic operative note template for practically every operation commonly performed. You can, therefore, generate these templates, save them on your own computer, and use those generic notes to create the specific one needed for each case. This strategy will not only save a lot of time, but it will also result in more organized, accurate, and thorough notes.

You should always make it a habit to go by the ICU at the end of your day to check in on your patient again. You will be surprised how often there will be some question that you can answer that might save you a call later in the night or there may be some evidence that suggests that the patient is not doing as well as you had hoped. Again, it is much better to sort those 'end of the day' issues out in person early in the evening rather than trying to do so by phone after you have left for the day.

It is worth adding here that you should remain involved in the care of your patients in the ICU, even if there is a lot of help available, ranging from faculty intensivists to more junior residents. Not only will the patients get better care when you are involved, but you will also learn a lot about managing the care of cardiothoracic surgery patients in the ICU.

\section{PART IV - REFLECTING ON YOUR EXPERIENCES, FORMALLY \& INFORMALLY}

We do not learn from experience. We learn from reflecting on experience.

—John Dewey

It is crucial, at every stage of your career, to reflect on what you have done during every operation, even those that seemed to have gone precisely according to plan. If you incorporate this type of review into your routine, you will be amazed at how often you will have some substantive reflections about your cases. Years ago, we followed Dr. Frank Spencer's advice to dictate a note to ourselves after each operation [Spencer, 1979] Later, it seemed that it was likely preferable to write these reflections in notebooks by hand, partly because writing by hand utilizes several different parts of your brain, which is said to enhance both memory and creativity, and also because you can use drawings to augment your thoughts. Furthermore, these reflections will often prompt subsequent conversations with others about what was done in a given case. When feasible, it is optimal to write out these reflections soon after creating the operative note, as the process of creating the formal op note will often call to mind some thoughts that you would like to 'hold on to' or even look up or discuss with someone later.
I write to find out what I think.

- Stephen King

These reflections on what you have done can, and should, come at three levels or time points. One time point is, of course, at the time you experience something, whether that be an action taken or feedback provided. A good example of this process is experienced when learning to perform coronary artery graft anastomoses. With the time constraints that obviously exist under these conditions, you must press on with the operation, while committing to later contemplation of any feedback given or reflections made. We have used the analogy of minimizing a window on a computer that can, later, be reopened for further contemplation. [Tribble: String Music, Mental Strategies I \& II]

The next time point for reflection should be shortly after 'the learning opportunity' has occurred. Reflecting at this stage can involve contemplation on your own, seeking advice from other sources, and writing, as writing things down will, in the long run, be more memorable and can also inspire additional, sometimes creative, reflections. As noted earlier, we believe that the best process for noting these reflections involves writing in a bound notebook that you keep on your desk, with the intention of adding to your notes at least a time or two in the hours or days that follow your experiences. Again, it is worth noting that writing by hand in such a notebook also affords the opportunity to draw as well as to write. As teachers of surgery residents, we have also found that notes written in this manner can facilitate the provision of accurate, efficient, and timely feedback to our protégés. [Tribble, In Your Own Words...]

\section{Every damn thing is your own fault, if you're any good. —Ernest Hemingway}

Of course, you will have occasion, more often than you would wish, to discuss some aspect of a case or a patient's course in a more formal setting such as Morbidity \& Mortality Conference. You should prepare as thoroughly for your presentations at M\&M Conference as you would for an operation. You owe your current patient, your future patients, your colleagues, and yourself a 'quiet hearing,' with proper contemplation of what might have been done differently and what lessons have been learned. [Tribble: Practical Minded Obsession]

Perfection is not attainable, but, if we chase perfection, we can catch excellence.

-Vince Lombardi, Coach of The Green Bay Packers, 1959-1967

\section{PART V - ENERGY \& HEALTH: DEVELOPING A} SUSTAINABLE DESIGN

Does how you feel affect the way you perform?

-Doug Newburg

Doug Newburg, in his book The Most Important Lesson No One Ever Taught Me, poses this question: Does how you 
feel affect the way the way you perform? The answer to that question is, obviously: Yes, of course!

Therefore, it is your responsibility to optimize how you feel, in every way that you can, as you perform in your various roles, day to day.

Successful outcomes are satisfying and awards are gratifying, but the joy of Surgery is in the process: the daily events of caring for patients, thinking about a new problem, or thinking anew about an old one, the unpredictability and ever-changing novelty of events, and the physical pleasure of working with your hands.

-Henry Buchwald, MD

Another important question you must ask yourself is: Where do I get my energy? And, a related question to ask about any activity or endeavor is: Does that activity create energy or does it take energy away? There are many things that, upon reflection, do bring or create energy for most of us, such as learning, talking to patients and their families, working with good teammates, and, especially, for us as craftsmen (or 'craftspeople'), working with our hands while doing procedures. [Crawford, Shop Class as Soulcraft] Again, remember that you are a role model. That is, be committed to paying attention to these issues both for yourself and to be a role model for others.

We have previously written at length about health maintenance in the busy lives we all lead training in or practicing Cardiothoracic Surgery. [Always Keep Your Clothes in the Car, 2016] However, we will reiterate some of the primary points we have made previously to emphasize them for those beginning this final stage of their formal training. The amount of time available for exercise and healthy living is, admittedly, limited for most of us. So, what are some ways that you can maintain at least a semblance of fitness and health as a busy resident?

One strategy that we have used is to allocate about 30 minutes each morning to do a short workout. It can, after all, be motivating to roll out of bed just a click earlier if you have something you like to do 'on the docket.' You can make this strategy work without going anywhere and without fancy equipment. Here are some suggestions for the gear you might use for a minimalist workout (all of which is affordable, especially if you can buy them used somewhere):

- A yoga mat

- A pull-up \& dip station

- A set of dumbbells

We have also found that creating a checklist of what you plan to do in your workouts can be inspiring. If you follow your checklist and record what you have done, you will most certainly feel a sense of satisfaction. You can tailor your plan so that it makes sense for you. We have added pushups and sit-ups to our morning routine, as well as about 5 yoga poses, pull ups, and dips. You will likely want to add some kind of aerobic workout to your weekly plan, with the goal of doing that activity on a weekend day. We have used hiking, swimming, running, basketball, rowing, and bike riding ourselves. Make whatever you do as sensible, fun, safe, and sustainable as is practical. Furthermore, it can be all the more fun to involve friends or family in these activities when feasible. Here are a few pictures of such activities done with family and friends:
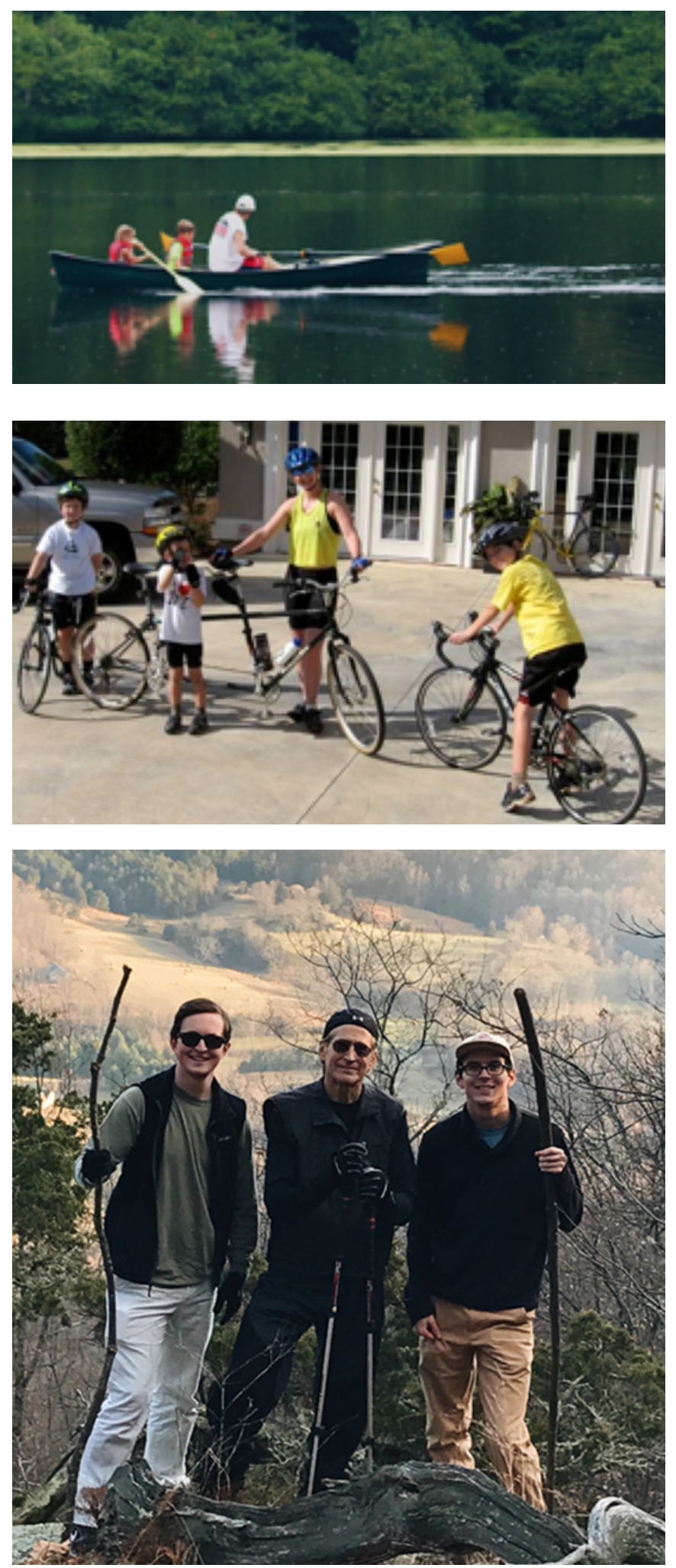
You can also make use of the stairs in your hospital. Walking up stairs is obviously a reasonable workout. You can vary your routine by taking them two at a time or by focusing on staying on your toes. Walking downstairs can be a bit of an upper body workout, if you 'swing down' the stairs with your arms on the rails. You will likely be more inspired to do all of these things if you 'log' these activities in your exercise log book. We have also written about optimal dietary practices. Think about the food you eat almost like you would taking medications. As the old saying goes, 'food is a drug.'

It should be said explicitly that, as part of your attention to health maintenance, you should also work to maintain your personal relationships, which for many senior surgical trainees will include a spouse and children. While we could (and might someday) write an entire book just on this subject, we will make a few suggestions, some of which you may find useful. While the idea of 'quality time' may sound like a cliché, it really is not. Consider organizing a 'date night' once a week (complete with baby sitters, if necessary) to have at least one 'adult conversation' with your partner each week. Try your best not to complain at home about what you are doing at work. Complaining will not make you nor your partner feel any better about what you are doing for a living, so avoid the common tendency to complain about everybody and everything but, rather, try to find a story to tell of a great case, something you learned, or a neat interaction with a patient, family, or colleague. And, remember to thank your partner or friends for their support. As some who have lived in or around intense environments, from surgical training to the military, have pointed out, if you and / or your partner choose to act like you don't care about the time and intensity of a challenging part of your lives, you may actually come to believe that you don't care, and that can be disastrous for all concerned. [Ricketts, 2014]

Nothing will sustain you more potently (in your bumdrum routine) ... than the power to recognize the true poetry of life.... the poetry of the commonplace, of the ordinary man, of the plain, toilworn woman, with their loves and their joys, their sorrows and their griefs.

—William Osler, MD

Finally, you will (or should) get energy from the patients you care for, as well as from the procedures that you perform. Both our patients and the procedures we perform can be part of 'the poetry of life' as Dr. Osler famously proclaimed. [Tribble, I Call That a Bargain]

\section{PART VI - BEING A TEAM LEADER, A TEACHER, AND A ROLE MODEL}

You will be among the best all-round doctors in the hospital. Act like it. And, realize that, for better or for worse, you will be a role model for many others on your team. Therefore, you need to speak, dress, and behave in a way that inspires confidence. It is worth understanding the 'languages' of our realm, which include the language of science, the language of performance, and the language of learning and memory. [Tribble, Merrill, 2014]

I'll tell you what leadership is. It's persuasion and conciliation and education and patience. It's long, slow, tough work. That's the only kind of leadership I know, believe in, or will practice.

-Dwight D. Eisenhower

To be a bit more granular, first and foremost, you need to listen to everyone on your team. They will all have different perspectives. One of our favorite professors liked to start every operation by saying "everyone at this table will have, by definition, a different view and a different perspective on what is being done. If you see something, say something."

That seemingly small gesture will almost always be received as both welcoming and empowering by all who are part of your team.

We remember .....
$10 \%$ of what we read.
$20 \%$ of what we bear.
$30 \%$ of what we see.
$50 \%$ of what we see and hear.
$70 \%$ of what we discuss with others.
$80 \%$ of what we experience.
$95 \%$ of what we teach to someone else.
-Edgar Dale

You should also always strive to be at least somewhat in a teaching mode, thinking about teaching everyone on your team, as much as is practical. Not only will they learn from your teaching, but so will you. After all, there is truth to the old adage that 'to teach is to learn twice.'

Kitty K: Dr. Muller would usually use a 3-0 stitch for this purpose....

Resident: Kitty, I was just about to ask if you could swap that 2-0 stitch I requested for a 3-0!

You will have a hard time finding a surgeon who did not have a favorite scrub nurse during their residency years who, often gently, nudged trainees in the right direction, based on their years of experience with the cases being done. Asking the experienced folks in your operating room for advice is, obviously, the senior resident's extrapolation of what we all learned to ask, as more junior residents on the wards or in the ICU, which was some version of "what do you usually do about that?"

Diplomacy is the art of telling people to go to bell in such a way that they ask for directions. [Putterman, 2019]

You must be discrete about many of the conversations you will have, not only while a resident, but also throughout your career. Some conversations should be held behind closed doors. If in doubt, shut the door. It certainly seems that there are always plenty of people working in complex environments who like a bit of 'palace intrigue.' And, if you are not already 
aware of this principle, it is worth noting that 'palace intrigue' is rarely, if ever, good for anyone in the equation, including you. You should strive to make your first response to any observation conveyed to you in a conversation be "what might be true of that?' [Suzette Haden Elgin]

Basically, your goal should be to optimize the harmonious functioning of your teams. Strive to use the language of commitment, rather than the language of complaint. You want to create an environment of harmony, learning, and performance. Some have described this spirit as genius loci, which roughly translates to 'the spirit of a place.' [Edlich's Academical Village, Towler \& Tribble. The Way We Talk is the Way We Teach, Tribble \& Merrill]

Sometimes you will have the opportunity to easily and efficiently draw in some of the younger members of your team. There is almost always at least one stitch in an operation that even the most inexperienced medical student can be allowed to place. For instance, we have often allowed a third year medical student to place one valve suture in the sewing ring of a prosthetic valve or in the non-coronary cusp of the aortic annulus during an aortic valve replacement. It is nigh unto impossible for even a beginner to do that wrong, with proper guidance. Once that stitch is placed, you can even ask the circulating nurse to call that student's mother on the phone and announce that her daughter or son has just done an important part of a cardiac surgical operation. Everyone involved will be wound up about that event, likely for a long time afterwards. We have had the pleasure of involving students in this way numerous times over the years.

Finally, never underestimate the value of peer to peer brainstorming. Often your co-residents will have only recently figured out the 'just right way' to do something that you are struggling with. That is, they will remember what it was like not to know (which may NOT be true of your faculty teachers) and how they came to know and understand something. We are fairly sure that we learned at least as much from our peers as we did from our professors during our residencies.

\section{PART VII - SUMMARY: THE DAYS ARE LONG BUT THE YEARS ARE SHORT}

My mission in life is not merely to survive, but to thrive. And to do so with some passion, some compassion, some humor, and some style. -Maya Angelou [citation]

There is obviously much to be learned in your Thoracic Surgery Residency about the medical conditions you will encounter and the strategies used to treat those conditions. However, we believe that you can accomplish your goals if you approach this final stage of your formal training with passion, humor, compassion, and style.

I believe that man will not merely endure: he will prevail ..... because be has a soul, a spirit capable of compassion and sacrifice and endurance.

-William Faulkner, in his Nobel Prize Acceptance Speech [citation]
REFERENCES

Bernstein L. https://www.classicfm.com/composers/bernstein-l/guides/ leonard-bernstein-quotes/great-things/ (Accessed 10-5-21)

Chiles W. 1977. Storm Passage: Alone Around Cape Horn. Times Books, a Division of Quadrangle / The New York Times Book Company, Inc. New York.

Peabody F. https://libquotes.com/francis-weld-peabody (Accessed 10-5-21)

Maddaus, M. Clarity in Complexity. https://michaelmaddaus.com/ (Accessed 10-5-21)

Halifax, J. Buoyancy Rather than Burnout in Our Lives, an Interview with Joan Halifax by On Being's Krista Tippett. https://www.dailygood. org/story/1864/joan-halifax-buoyancy-rather-than-burnout-in-ourlives/ (accessed 9-28-21)

Arthur Ashe. https://101quotesabout.blogspot.com/2016/03/arthurashe-quotes-start-where-you-are-use-what-you-have-do-what-you-can. html (Accessed 10-5-21)

Waters D. 1995. A Heart Surgeon's Little Instruction Book. https:// archive.org/details/aheartsurgeonslittleinstrucionbook/page/n13/ mode/2up (Accessed 10-5-21)

Theodor Kocher. http://www.lessismoremedicine.com/quotes (Accessed 10-5-2021)

Tribble C. 2019. Are You Making Yourself Clear? You Can't Communicate, or Think, Effectively If You Can't Write Clearly. The Heart Surgery Forum 22: 121-126.

Tribble C. 2016. Gimme 3 Steps (With a Nod to an American Rock Song from the 1970's). The Heart Surgery Forum, 19: E080-E081.

Elsey J. 2021. Reflections on Surgical Practice: Lessons Learned Along the Way and Notes to My Young Colleagues. J Am Coll Surg, in press. https://doi.org/10.1016/jamcollsurg.2021.o7.686 (Accessed 10-5-21)

Whitson B. 2016. The devil is in the details. J Thorac Cardiovasc Surg 151:320-1.

Tribble C. 2016. Failing to Prepare is Preparing to Fail. Heart Surgery Forum 19 (3): 112-5.

Tribble C. 2020. The Well-Tempered Clinic: The Clinical and Educational Importance of Cardiovascular Surgical Clinics (With a nod to Johann Sebastian Bach). Heart Surgery Forum 23: 712-717,

All that Jazz, directed by Bob Fosse, 1979 https://www.shmoop.com/ quotes/its-showtime-folks.html (Accessed 10-5-21)

Tribble C, Julliard W. 2019. First, We Do Harm: Obtaining Informed Consent for Surgical Procedures. The Heart Surgery Forum 22: E423-E428.

Tribble C. 2016. Gimme Three Steps: Increasing Patient Satisfaction, Decreasing Physician Burnout. The Heart Surgery Forum 19 (2): 80-1.

Tribble C. 2017. Grandmother Rules: Crucial Conversations with Patients and Families. The Heart Surgery Forum, 20: E002-E006.

Tribble C. 2016. Always Keep Your Clothes in the Car. The Heart Surgery Forum 19 (5): 237-40.

Tribble C, Merrill W, Derryberry S, Parrino G. 2021. The Median Sternotomy: The Unkindest Cut of All? Pearls, Pitfalls, Aphorisms, \& Myths. The Heart Surgery Forum, 24: E267-E277.

Marvil P, Tribble C. 2017. Lessons from Crew Resource Management for Cardiac Surgeons. The Heart Surg Forum 20 (2): E077-081. 
Calland J, Guerlain S, Adams R, Tribble C, Foley E, Chekan E. 2002. A systems approach to surgical safety. Surg Endosc 16: 1005-14.

Grillo H. 2016. Writing Things Down. Personal Communication, Pierre de Delva.

Tribble C. 2017. Grandmother Rules: Crucial Conversations with Patients and Families. The Heart Surgery Forum, 20: E002-E006.

Dewey J. https://www.goodreads.com/author/quotes/42738.John_Dewey (Accessed 10-5-21)

Spencer F. 1979. Competence and compassion: two qualities of surgical excellence. Bulletin of the American College of Surgeons November 1979:15-22.

King S. https://www.goodreads.com/quotes/134620-i-write-to-find-outwhat-i-think (Accessed 10-5-21)

Tribble C, Derryberry S. 2018. String Music: Creating Coronary Artery and other Vascular Anastomoses. The Heart Surg Forum 21: 497-506.

Tribble C. 2020. The Mental Strategies of Surgeons: A Primer - Part I. The Heart Surgery Forum 23 (6): E927 - E208.

Tribble C. 2021. The Mental Strategies of Surgeons: A Primer - Part II. The Heart Surgery Forum 24 (1): E201 - E936.

Tribble C, Merrill W. 2016. In Your Own Words: Toward a More Perfect Union of Patient Care and Education. Ann Thorac Surg 101: 837-40.

Hemingway E. https:/quotefancy.com/quote/803621/ErnestHemingway-Every-damn-thing-is-your-own-fault-if-you-areany-good\#: : text=Ernest $\% 20 \mathrm{Hemingway} \% 20$ Quote $\% 3 \mathrm{~A} \% 20$ $\%$ E2 \% $80 \% 9$ CEvery $\% 20$ damn, if $\% 20$ you $\% 20$ are $\% 20$ any $\% 20$ good.\% E2\% 80\%9D (Accessed 10-5-21)

Tribble C. 2016. A Practical Minded Obsession with the Possibility and Consequence of Failure. The Heart Surgery Forum 19 (1): 1-4.

Lombardi V. https://www.goodreads.com/quotes/392543-perfection-isnot-attainable-but-if-we-chase-perfection-we (Accessed 10-5-21)

Newburg D. 2009. The Most Important Lesson No One Ever Taught Me. (Available on Amazon.com, Google Books, and Barnes \& Noble)

Buchwald H. 2015. One Surgeon's Principles. Bulletin of The ACS. https://bulletin.facs.org (Accessed 10-5-21)

Crawford M. 2009. Shop Class as Soulcraft. The Penguin Press. New York.

Tribble C. 2016. Always Keep Your Clothes in the Car. The Heart Surgery Forum 19 (5): 237-40.

Ricketts, A. 2014. No Man's War: Irreverent Confessions of an Infantry Wife. Counterpoint Press, Berkley, California.

Osler, W. 2001. 'The Student Way of Life' in A Way of Life \& Other Addresses. Duke University Press 2001: 305-330.

Tribble C. 2018. I Call That A Bargain. The Heart Surgery Forum 21 (3): E229-234.

Tribble C, Merrill W. 2014. The Way We Talk is the Way We Teach. J Thorac Cardiovasc Surg 147: 1155-9.

Eisenhower D. https://www.linkedin.com/pulse/what-general-eisenhower-reminded-me-leadership-phyllis-wise/ (Accessed 10-5-21)

Edgar Dale. https://uh.edu/ dsocs3/wisdom/wisdom/we_remember.pdf (Accessed 10-5-21)

Putterman, S. 2019. POLITIFACT. https://www. politifact.com/factchecks/2019/sep/20/blog-posting/ no-evidence-churchill-said-quote-about-diplomacy-b/

(Accessed $10-5-21)$

Elgin, SH. 1985. The Gentle Art of Verbal Self-Defense. Dorset House Publishing, Inc. New York.

Towler M, Abidin M, Tribble C. 1993. Edlich's Academical Village. J Emerg Med 11: 353-7.

Tribble C, Merrill W. 2014. The Way We Talk is the Way We Teach. J Thorac Cardiovasc Surg 147: 1155-9.

Angelou M. https://www.goodreads.com/quotes/11877-my-mission-inlife-is-not-merely-to-survive-but (Accessed 10-5-21)

Faulkner W. https://www.nobelprize.org/prizes/literature/1949/faulkner/ speech/ (Accessed 10-5-21)

Moore H, Galloway L. 1992. We Were Soldiers Once ... and Young The Battle that Changed the War in Vietnam. Ballantine Books, New York.

\section{ADDITIONAL REFERENCES}

Newburg D. 2010. The Little Book of Big Performance. https://feelin50. files.wordpress.com/2010/01/lbbp-web.pdf (Accessed 10-5-21)

Pasque M. 2021. Getting the Most from Your Cardiothoracic Surgical Training: It's All About Behavior. J Thorac Cardiovasc Surg, in press. https://doi.org/10.1016/j.jtcvs.2021.06.054

Chestnut D. 2017. On the Road to Professionalism. Anesthesiology. 126: 780-6. (Cited resume versus eulogy virtues, from David Brooks.)

Kemp M, Williams A, Rivard S, Perrone E, Sandhu G, Telem D. 2021 Physician Heal Thyself: A Call to Action for Prioritizing Trainee Health. Ann Surg 274: e201-e202.

Lipsett P. 2021. Grit among US Surgical Residents - Food for Thought. JAMA Surg 156: 864.

Loftus T, Filiberto A, Rosenthal M, Arnaoutakis G, Sarosi G, Dimick J, Unchurch G. 2020. Performance Advantages for Grit and Optimism. Amer J Surg 220: 10-18.

Brooks D. The Road to Character. 2015. Random House, New York

Pfeiffer R. 1983. A Chance to Cut is a Chance to Cure. 4th Edition. Self-published.

Waters D. 1998. A Surgeon's Little Instruction Book. Quality Medical Publishing, Inc. St. Louis, Missouri

Dairywala M, Gupta S, Salna M, Nguyen T. Surgeon Strength: Ergonomics and Strength Training in Cardiothoracic Surgery, Seminars in Thoracic and Cardiovascular Surgery (2021), in press. https://doi. org/10.1053/j.semtcvs.2021.09.015

\section{AUTHORS' ACKNOWLEDGEMENTS}

CGT: Much of what we have learned about the issues addressed in this essay has, of course, come to us from a large number of mentors, friends, relatives, and colleagues. I will mention a few that deserve 'honorable mention' from me, including my father, David Tribble (a Thoracic Surgeon, who, in retrospect, was passing along many words of wisdom, starting when he was a medical student and I was a little kid, continuing for many decades afterwards), two of my brothers, 
Ben \& Reid Tribble (also surgeons, one primarily Vascular and one primarily Cardiac), a very wise friend and colleague, Doug Newburg (who has a PhD in Sports Psychology), one of my all-time best partners, Walter Merrill (also a Thoracic Surgeon, who has always had almost uncanny insights into surgical education and practice), and my wife, Megan (an OR nurse to this day and a sharp eyed editor of my often error riddled writings). The final tip of the cap goes to Lieutenant General Harold Moore and Joseph Galloway who co-authored one of the best known books about Vietnam, entitled We Were Soldiers Once.... And Young. While I do not believe that fighting wars and operating on people have all that much in common, one could be forgiven for thinking that they do.

NRT: I am forever indebted to the faculty at The University of Virginia (including my co-author) who taught me so much about how to be a successful TCV resident. The lessons and advice offered in this treatise are based both on firsthand experience and on learning from an excellent group of mentors. Enormous credit goes also to my wife, Julie, and our daughters, Emerson and Violet (who happened to be born two months prior to my own last year of training), as they kept me sane and grounded throughout my own TCV residency. 